
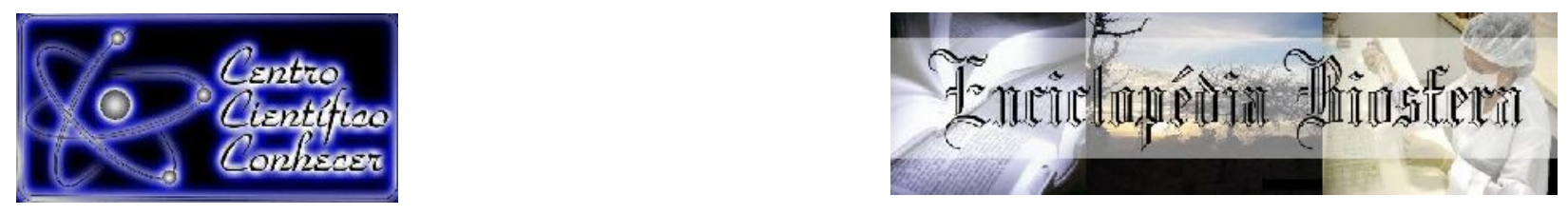

\title{
BOAS PRÁTICAS AGROPECUÁRIAS (BPA) NO CONTROLE E PREVENÇÃO DA MASTITE BOVINA - ESTUDO DE CASO
}

Valéria de Souza Cruz ${ }^{1}$, Raul Vargas Boechat ${ }^{2}$, Ítalo Câmara de Almeida ${ }^{3}$, Renata Cogo Clipes ${ }^{4}$, Dirlei Molinari Donatele ${ }^{5}$.

1 Graduanda em Ciências Biológicas Licenciatura da Universidade Federal do

Espírito Santo (vavcruz@hotmail.com) Alegre-Brasil

2 Graduando em Medicina Veterinária da Universidade Federal do Espírito Santo

3 Médico Veterinário do Hospital Veterinário da Universidade Federal do Espírito Santo

4 Professora Doutora do Instituto Federal de Educação, Ciência e Tecnologia do Espírito Santo

5 Professor Doutor do Departamento de Medicina Veterinária da Universidade Federal do Espírito Santo

Recebido em: 04/10/2019 - Aprovado em: 30/11/2019 - Publicado em: 15/12/2019 DOI: 10.18677/EnciBio_2019B9

\section{RESUMO}

O presente trabalho objetivou verificar se a implementação de Boas Práticas Agropecuárias (BPA) funcionam para controle e prevenção da mastite em uma propriedade de bovinocultura leiteira no município de Alegre, Espírito Santo. Foram realizados exames de mastite, por meio do teste da caneca de fundo preto e teste californiano de mastites (CMT) de todos os quartos dos bovinos em lactação em três períodos: D0 (antes da implantação das BPA); D3 (três meses após D0), e D6 (seis meses após D0), totalizando seis meses. Realizou-se a cultura e identificação bacteriana dos quartos positivos para mastite. Com o presente estudo verificou-se decréscimo superior a $27 \%$ na taxa de prevalência de bovinos com mastite subclínica e $45 \%$ na taxa de prevalência de quartos positivos, a partir da implementação das BPA na ordenha. O resultado da cultura, encontrou a presença do Staphylococcus spp. (54,1\%), Corynebacterium bovis (39,34\%), e Streptococcus spp. (6,55\%) nos quartos avaliados, evidenciando que a mastite presente na propriedade era contagiosa. Com o presente trabalho pode-se perceber que a utilização das BPA contribuíram para diminuição da prevalência da mastite subclínica na propriedade, mas para a prevenção e controle efetivo da mastite bovina torna-se necessário a continuação do acompanhamento e implementação das Boas Práticas Agropecuárias.

PALAVRAS-CHAVE: bovino, leite, mamite. 


\title{
GOOD AGRICULTURAL PRACTICES (GAP) IN THE CONTROL AND PREVENTION OF BOVINE MASTITIS
}

\begin{abstract}
The present work aimed to verify if the implementation of Good Agricultural Practices (BPA) works to control and prevent mastitis in a dairy cattle farm in city of Alegre, Espírito Santo. Mastitis examinations were performed using the black bottom mug test and the California mastitis test (CMT) of all quarters of lactating cattle in three periods: D0 (before BPA implantation); D3 (three months after D0), and D6 (six months after D0), totaling six months. The bacterial culture and identification of the positive rooms for mastitis were performed. The present study showed a decrease of over $27 \%$ in the prevalence rate of cattle with subclinical mastitis and $45 \%$ in the prevalence rate of positive quarters, from the implementation of BPA in milking. The culture result found the presence of Staphylococcus spp. (54.1\%), Corynebacterium bovis (39.34\%), and Streptococcus spp. (6.55\%) in the evaluated rooms, showing that the mastitis present in the property is contagious. With the present work it can be seen that the use of BPAs contributed to decrease the prevalence of mastitis in the property, but that for the prevention and effective control of bovine mastitis, it is necessary to continue the monitoring and implementation of BPAs.
\end{abstract}

KEYWORDS: Mastitis, Cows, Milk

\section{INTRODUÇÃO}

A mastite bovina caracteriza-se como a inflamação da glândula mamária, independente da causa e intensidade, sendo a doença mais comum nos rebanhos leiteiros. É complexa etiologicamente, pois apresenta caráter multifatorial, e se encontra abundantemente disseminada nos rebanhos leiteiros brasileiros, gerando grandes perdas econômicas na cadeia produtiva do leite. Pode ser identificada por alterações patológicas no tecido gandular e também por diversas alterações no leite, seja bacteriológica, química ou física (RIBEIRO et al., 2016). Normalmente apresenta caráter infeccioso, mas principalmente pela infecção bacteriana. De acordo com o tipo de agente infeccioso a mastite pode ser classificada em mastite contagiosa, causada por bactérias da microbiota dos animais, como o Staphylococcus aureus, Corynebacterium bovis e Streptococcus agalactiae, e a mastite ambiental por bactérias de origem ambiental, como a Escherichia coli, Klebisiella pneumoniae, Streptococcus dysgalactiae e Streptococcus uberis (ZIMERMANN; ARAUJO, 2017; DE SÁ et al., 2018).

Dependendo da forma de manifestação a mastite pode ser classificada como subclínica e clínica. Na forma subclínica, os animais não apresentam evidentes alterações no úbere nem sinais de desconforto, a composição física do leite também não sofre alterações, mas ocorrem alterações na sua composição química, destacando-se a diminuição das porcentagens de alguns constituintes do leite, como a lactose e sólidos totais, e o aumento da Contagem de Células Somáticas (CCS). Devido ao aumento da CCS, são utilizados testes indiretos como o Teste Californiano de Mastites (CMT), no diagnóstico da mastite subclínica. A forma clínica apresenta resposta inflamatória severa, podendo ocorrer em qualquer fase da vida do animal e causa mudanças no aspecto do úbere e leite, apresenta sinais evidentes, sendo possível observar quartos inchados e doloridos ao toque, elevação 
da temperatura, edema, aparecimentos de grumos ou pus no leite e endurecimento da glândula mamária. Para a detecção dessa forma da doença, são utilizados o exame físico do úbere e o Teste da caneca de fundo preto, realizado com os primeiros jatos de leite (TOZZETTI et al., 2008; LANGONI et al., 2017).

O teste da caneca de fundo preto é utilizado no diagnóstico da mastite clínica. Para a sua realização, os primeiros jatos devem ser descartados na caneca e se apresentarem grumos, o diagnóstico é positivo. Esse teste deve ser realizado em todos os animais e em todas as ordenhas. O CMT deve ser realizado anterior à ordenha e auxilia no diagnóstico da mastite subclínica, realizando uma estimativa do número de células somáticas do leite oriundo de cada quarto mamário. Por ser um teste simples e eficaz, é 0 mais utilizado para 0 diagnóstico, sendo recomendado que seja realizado mensalmente em todas as vacas em lactação (RIBEIRO et al., 2016).

Boas Práticas Agropecuárias (BPA) são definidas como o conjunto das atividades desenvolvidas dentro das propriedades rurais que objetivam garantir a segurança, bem-estar e saúde dos animais, participando das exigências da legislação, estando relacionadas com a sustentabilidade ambiental, agregação de valor e produção de derivados lácticos seguros para o consumo. São utilizadas para minimizar os riscos de contaminação microbiana ou física nas diversas etapas da produção leiteira e devem ser implantadas em toda a cadeia produtiva, ambicionando a inibição da multiplicação de micro-organismos indesejáveis ou até mesmo a eliminação. As BPA no momento da ordenha devem abranger três fatores fundamentais: a rotina de ordenha, o ordenhador e o ambiente, objetivando reduzir o nível de infecção do rebanho (ARCANJO et al., 2017; BRASIL, 2018).

A utilização das Boas Práticas Agropecuárias envolve várias ações que podem contribuir para diminuição da incidência e prevalência da mastite no rebanho leiteiro, acarretando assim, menores perdas econômicas para os produtores, e melhoria da qualidade do leite (DERETI et al., 2018). O objetivo do presente trabalho foi avaliar o impacto gerado pela implantação de um programa de boas práticas agropecuárias no controle e prevenção da mastite bovina em uma propriedade leiteira.

\section{MATERIAIS E MÉTODOS}

O presente estudo foi aprovado pelo Comitê de Ética de Uso de Animais do Instituto Federal do Espírito Santo (CEUA/Ifes), sob o número 23149.001271/201831. Foi selecionada uma propriedade de bovinocultura leiteira no município de Alegre/ES, que não possuía um programa de Boas Práticas Agropecuárias (BPA) implantado. O Termo de Consentimento Livre Esclarecido (TCLE) do projeto foi apresentado ao responsável pela propriedade e somente após a assinatura do termo, a mesma passou a participar do estudo. Foram observadas as variáveis relativas da propriedade, assistência técnica e também sobre as BPA antes e após a implantação do programa.

Realizou-se avaliações clínicas dos úberes de todas as vacas em lactação, com posterior análise da presença da mastite de todos os quartos mamários, por meio do teste da Caneca de Fundo Preto, para avaliar a presença de grumos, sangue e/ou pus, e o CMT®, para detectar a formação de gelatificação da reação, seguindo as orientações do fabricante.

Coletou-se amostras de leite dos quartos positivos no o teste da caneca de funcho preto e/ou do CMT, após a prévia lavagem do quarto, secagem em papel 
toalha e antissepsia com álcool 70\%. Aproximadamente $5 \mathrm{~mL}$ de leite foi coletado em frasco estéril de tampa rosqueável, identificado com o número do animal e o quarto mamário, sendo acondicionados em caixas isotérmicas com gelo e enviadas ao Laboratório de Inspeção de Produtos de Origem Animal (LIPOA) do Hospital Veterinário (Hovet) da Universidade Federal do Espírito Santo (UFES), onde foram realizadas as análises microbiológicas do leite.

As amostras de leite foram inoculadas em placas de Petri contendo Ágar Infusão Cérebro Coração $(\mathrm{BHI})$, meio de cultura não seletivo, e incubadas a $37^{\circ} \mathrm{C}$ por 24 a 48 horas, para realização do isolamento e identificação dos microorganismos, conforme Quinn et al. (2005).

De posse dos resultados laboratoriais e das observações dos pesquisadores, foi proposto um programa de BPA na propriedade, para controle e prevenção da mastite e para melhoria da qualidade do leite na propriedade. Foram realizadas observações e coletas durante seis meses em 2018. Classificou-se a primeira coleta como D0, e a partir da qual as BPA começaram a ser implantadas; D3, três meses após a primeira coleta e três meses após a implantação das BPA na propriedade; e D6, seis meses após à implantação das BPA.

No programa de BPA proposto para a propriedade foi sugerido e implantado a realização diária da lavagem da sala de ordenha, da linha de ordenha, pré e pósdipping, teste da caneca de fundo preto, e que mensalmente fosse realizado o CMT em todos os animais que estavam em lactação. Os dados obtidos por meio das coletas e dos exames laboratoriais foram armazenados em planilhas do Microsoft Excel 2007, para posterior tabulação e análise descritiva dos dados. No final dos seis meses de observação, foi calculada a prevalência da mastite antes e depois da implantação das BPA, por meio das fórmulas de prevalência descritas por Rouquayrol e Almeida Filho (2009).

\section{RESULTADOS E DISCUSSÃO}

A propriedade rural estudada nesse trabalho está situada na região do Caparaó, no município de Alegre, no estado do Espírito Santo, e apresenta a bovinocultura leiteira como principal fonte de renda, com sistema de ordenha mecanizada duas vezes ao dia, e presença de três funcionários durante o estudo. No início da pesquisa a propriedade contava com 42 bovinos em lactação. Esse número foi diminuindo, atingindo o valor de 35 animais em lactação no D6, pelo fato de alguns terem entrado no período seco.

No D0 foi possível constatar que não havia casos de mastite clínica e altas taxas de mastite subclínica na propriedade (tabela 1), que pode ser explicada pela falta de conhecimentos e implementação das medidas de controle e prevenção para mastite, e da não realização das BPA. Segundo Arcanjo et al. (2017), para o controle eficaz da mastite, uma propriedade leiteira deverá implantar um programa com seis pontos básicos: correta rotina de higiene do ordenhador e animal na ordenha; tratamento de mastites clínicas durante a lactação com corretos procedimentos com o antibiótico; antibioticoterapia de secagem em todos os animais; limpeza, manutenção e adequado funcionamento dos equipamentos de ordenha; identificação, segregação e descarte de vacas cronicamente infectadas; e manejo adequado do ambiente de permanência dos animais, tanto no requisito de higiene como de bem estar. 
Após o D0, foi criado um programa de BPA que atendiam às necessidades da propriedade. Os funcionários receberam capacitação sobre as mesmas e como implantá-las na rotina de ordenha da propriedade. O objetivo da capacitação foi demonstrar aos funcionários a importância que possuem na produção, pois como descritos por Costa (2016) e Dereti (2017a), a qualificação dos funcionários é primordial para a implantação e consolidação das BPA na propriedade.

$\mathrm{Na}$ capacitação dos funcionários, por meio de palestras, dia de campo e material impresso, foram abordados diversos itens, como a lavagem dos tetos e realização de pré e pós-dipping, a importância da realização dos testes da caneca de fundo preto e CMT, a relevância da lavagem da sala de ordenha e da ordenhadeira, da realização da linha de ordenha, seguir o tratamento da mastite segundo as recomendações do médico veterinário, bem estar animal, e de servir alimento aos animais logo após a ordenha. A capacitação dos funcionários foi baseada nas orientações básicas para implantação das BPA em uma propriedade leiteira propostas por Dereti (2017b), e pelas observações dos pesquisadores durante o estudo. Na tabela 1 estão apresentados os resultados das taxas de prevalência de mastite clínica, subclínica e de quartos positivos nos diferentes períodos D0, D3 e D6.

Durante os períodos avaliados não foram encontrados casos de mastite clínica. No período D0, $61,54 \%$ dos quartos mamários, e $61,9 \%$ dos animais em lactação apresentaram mastite subclínica, o que demonstrou uma alta prevalência da doença na propriedade, ressaltando a grande importância dessa doença para a bovinocultura leiteira regional e nacional, corroborando com os estudos de diferentes autores, como Martins et al. (2010), Senhorello et al. (2013), Saab et al. (2014), Martins et al. (2015), Assis et al. (2017), que encontraram uma alta prevalência de mastite subclínica em diversas regiões do Brasil.

Vale ressaltar que a higiene para a obtenção do leite e a sanidade dos animais são de grande relevância, pois com a presença da mastite a produtividade e a composição do leite podem sofrer alterações, causando prejuízos nos rendimentos do leite e seus derivados (DEMEU et al., 2015; RODRIGUES et al., 2018).

TABELA 1 Prevalência da mastite clínica e subclínica dos bovinos leiteiros com a implantação das Boas Práticas Agropecuárias (BPA) em uma propriedade leiteira no município de Alegre/ES.

\begin{tabular}{lcccc}
\hline \multicolumn{1}{c}{ Item } & \multicolumn{3}{c}{ Períodos } \\
\cline { 3 - 5 } \cline { 3 - 4 } \cline { 3 - 4 } Número de animais & & D0 & D3 & D6 \\
\cline { 1 - 4 } $\begin{array}{c}\text { Taxa de prevalência de } \\
\text { mastite clínica }\end{array}$ & 42 & 40 & - \\
$\begin{array}{c}\text { Taxa de Prevalência de } \\
\text { mastite subclínica }\end{array}$ & & - & $34,28 \%$ \\
$\begin{array}{c}\text { Taxa de prevalência } \\
\text { quartos positivos }\end{array}$ & $61,9 \%$ & $35 \%$ & $15,83 \%$ \\
& $61,54 \%$ & $19,49 \%$ & \\
\hline D0 (Período antes da implantação das BPA); D3 (três meses após D0); e D6 (seis meses após D0)
\end{tabular}


O resultado cultura dos casos de mastite subclínica evidenciou a maior presença de Staphylococcus spp. (54,1\%), seguida por Corynebacterium bovis $(39,34 \%)$ e Streptococcus spp. $(6,55 \%)$ nos quartos avaliados, demostrando que a mastite presente na propriedade era a contagiosa. A elevada ocorrência de mastite contagiosa encontrada, corrobora com os estudos de Barbalho e Mota (2001), Saab et al. (2014), Da Cunha et al. (2015), Assis et al. (2017), e De Sá et al. (2018), que descrevem esses patógenos como os principais agentes etiológicos da mastite bovina contagiosa em diferentes regiões do Brasil.

A propriedade no período D0, não realizava os testes de caneca de fundo preto, CMT, pré-dipping, linha de ordenha, e esporadicamente o pós-dipping era realizado, demonstrando que as BPA não eram utilizadas na ordenha, o que pode ter favorecido a disseminação dos patógenos no rebanho. Segundo Lange et al. (2017) que os principais fatores de risco para ocorrência de mastite subclínica são os ligados diretamente ao momento da ordenha.

Foi possível observar um decréscimo de aproximadamente $27 \%$ na taxa de prevalência dos animais com mastite subclínica, e mais de $45 \%$ na taxa de prevalência de quartos positivos para mastite subclínica após seis meses da implementação das BPA no processo de ordenha, comprovando que sua implantação é eficaz no controle e prevenção da doença. A implantação da BPA na ordenha, além de diminuir a ocorrência de mastite, contribuirá para melhoria da qualidade do leite, como descrito por Vallin et al. (2009) no Paraná, e Copetti et al., (2018) no Rio Grande do Sul, que observaram melhoria da qualidade do leite, a partir da implantação de boas práticas de higiene na ordenha.

A implantação e o acompanhamento das BPA em uma propriedade são primordiais para o controle e prevenção da mastite bovina, e também para a melhoria da qualidade do leite e rentabilidade do produtor. A identificação desses micro-organismos destaca a necessidade da adoção das BPA, uma que se tratam de patógenos causadores de mastite contagiosa, na qual o animal é o reservatório da doença.

Identificar os fatores necessários para a ocorrência de mastite é um dos fundamentos dos programas de controle e prevenção. Com o uso dessas informações, as infecções podem ser prevenidas com intervenções que impeçam sua introdução e disseminação entre o rebanho. Em qualquer programa de controle é imprescindível ser priorizado o treinamento e a capacitação da mão-de-obra. As BPA contribuíram para a diminuição da prevalência da mastite na propriedade de bovinocultura leiteira, mas torna-se necessário a continuação do acompanhamento e utilização delas visando prevenção, controle efetivo e permanente da mastite bovina na propriedade.

\section{CONCLUSÃO}

A implementação das boas práticas agropecuárias contribuíram para a diminuição da prevalência da mastite subclínica na propriedade estudada.

\section{REFERÊNCIAS}

ARCANJO, A.H.M.; OLIVEIRA, P.C.S.; MOREIRA, L.C.; JAYME, C.G.; SOARES, N.A.; DE OLIVEIRA, A. R.; PEREIRA, K.A.; NOGUEIRA, M.A.R. Programa dos Seis Pontos de Controle da Mastite em Rebanhos Leiteiros. Global Science and 
Technology, Rio Verde, v.10, n.01, p.78 - 88, jan/abr. 2017. Disponível em: https://rv.ifgoiano.edu.br/periodicos/index.php/gst/article/view/860.

ASSIS, A. A.; FAÉ, C.B; DONATELE, D.M.; BARIONI, G.; CLIPES, R.C.; et al. Prevalência e etiologia a mastite bovina em municípios da região do Caparaó/ES. Revista Acadêmica: Ciência Animal, v. 15, n. Suppl 2, p. 285-286, 2017.

https://periodicos.pucpr.br/index.php/cienciaanimal/article/view/17331/16614

BARBALHO, T. C.F.; MOTA, R. A. Isolamento de agentes bacterianos envolvidos em mastite subclinica bovina no Estado de Pernambuco. Revista Brasileira de Saúde e Produção Animal, v. 2, n. 2, 2001. Disponível em: http://revistas.ufba.br/index.php/rbspa/article/viewArticle/604

BRASIL. Ministério da Agricultura, Pecuária e Abastecimento. Instrução normativa no 77, de 26 de novembro de 2018. Disponível em: http://sistemasweb.agricultura.gov.br/sislegis/action/detalhaAto.do?method=consultar LegislacaoFederal.

COPETTI, K.L.; ULSENHEIMER, B.C.; VIERO, L.M. Boas práticas de higiene durante a ordenha. Brazilian Journal of Animal and Environmental Research. v. 1, n. 1, p. 179-187, jul./set. 2018. Disponível em:

http://brazilianjournals.com/index.php/BJAER/article/view/739/632

COSTA, H. B. A. Avaliação dos principais programas de boas práticas agropecuárias implantados no Brasil para promover a sustentabilidade da cadeia leiteira. 2016. 132p (Dissertação de Mestrado em Ciências Animais). Faculdade de Agronomia e Medicina Veterinária, Universidade de Brasília, Brasília, DF, Brasil. Disponível em: http://repositorio.unb.br/handle/10482/21050

DA CUNHA, A.D.; BRAGANÇA, L.J.; QUINTÃO, L.C.; SILVA, S.Q.; DE SOUZA, F.N.; CERQUEIRA, M.M.O.P. Prevalência, etiologia e fatores de risco de mastite em rebanhos leiteiros de Viçosa-MG. Acta Veterinária Brasilica: v. 9, n. 2, 2015. Disponível em: https://periodicos.ufersa.edu.br/index.php/acta/article/view/5262

DEMEU, F.A.; DA ROCHA, C.M.B.M.; DA COSTA, G.M.; DOS SANTOS, G.; NETO, A.F. Influência da escala de produção no impacto econômico da mastite em rebanhos bovinos leiteiros. Revista Ceres, v. 62, n. 2, março-abril, 2015. Disponível em: $\quad$ http://www.scielo.br/scielo.php?script=sci_abstract\&pid=S0034737X2015000200167\&lng=en\&nrm=iso\&tlng=pt 
DERETI, R.M. Importância e diagnóstico das boas práticas agropecuárias em sistemas de produção leiteira. In: ZANELLA, M.B.; DERETI, R.M. (Ed). Boas práticas agropecuárias na produção de leite: da pesquisa para o produtor. Pelotas: Embrapa Clima Temperado, 2017a. p.9-14. Disponível em: http://wp.ufpel.edu.br/govi/files/2017/12/Documento-EMBRAPA-439.pdf

DERETI, R. M. Diagnóstico de boas práticas agropecuárias e ajuste de nãoconformidades em sistemas de produção de leiteira. 2017b. $107 \mathrm{f}$. Tese (Doutorado em Produção Animal) - Programa de Pós-Graduação em Zootecnia, Universidade Federal de Pelotas, Pelotas, Brasil. Disponível em: https://www.researchgate.net/profile/Rogerio_Morcelles_Dereti/publication/33107398 6_Diagnostico_de_boas_praticas_agropecuarias_e_ajuste_de_naoconformidades_em_sistemas_de_producao_leiteira/links/5c645db8a6fdccb608c105c c/Diagnostico-de-boas-praticas-agropecuarias-e-ajuste-de-nao-conformidades-emsistemas-de-producao-leiteira.pdf

DERETI, R.M.; GONÇALVES, E.B.; ZANELA, M.B.; SCHAFHAUSER, J.J.; ALVARENGA, M.B. Boas práticas agropecuárias na pecuária leiteira. Revista de Política Agrícola. ano XXVII, n.4, out/nov/dez, 2018. Disponível em: https://www.researchgate.net/profile/Rogerio_Morcelles_Dereti/publication/33375929 3_Ano_XXVII_-N_o_4_-

Out_Boas_praticas_agropecuarias_na_pecuaria_leiteira/links/5d02a7bba6fdccd 1309 91d12/Ano-XXVII-N-o-4-Out-Boas-praticas-agropecuarias-na-pecuaria-leiteira.pdf

DE SÁ, J.P.N; FIGUEIREDO, C.H.A; NETO, O.L.S; ROBERTO, S.B.A; GADELHA, H.S; et al. Os principais microrganismos causadores da mastite bovina e suas consequências na cadeia produtiva do leite. Revista Brasileira de Gestão Ambiental, v.12, n.1, p.01-13, 2018. Disponível em: https://www.gvaa.com.br/revista/index.php/RBGA/article/download/5785/4963

LANGE, M.J.; ZAMBOM, M.A.; POZZA, M.S.S.; SIMÕES, G.H.; FERNANDES, T.; TININI, R.C.R.; FORNARI, J.; ANSCHAU, F.A. Tipologia de manejo de ordenha: análise de fatores de risco para a mastite subclínica. Pesquisa Veterinária Brasileira. v. 37, n. 11, p.1205-1212, novembro, 2017. Disponível em: https://www.researchgate.net/profile/Tatiane_Fernandes2/publication/323298489_Tip ologia_de_manejo_de_ordenha_analise_de_fatores_de_risco_para_a_mastite_subcl inica/links/5b292b810f7e9b1d0035a0fc/Tipologia-de-manejo-de-ordenha-analise-defatores-de-risco-para-a-mastite-subclinica.pdf

LANGONI, H.; SALINA, A.; OLIVEIRA, G.C.; JUNQUEIRA, N.B.; MENOZZI, B.D.; JOAQUIM, S.F. Considerações sobre o tratamento das mastites. Pesquisa Veterinária Brasileira. v. 37, n. 11, 2017. Disponível em: https://www.google.com/url?sa=t\&rct=i\&q=\&esrc=s\&source=web\&cd=1\&ved=2ahUK Ewj 5PSu54DIAhUmGbkGHavZCI4QFjAAegQIAhAC\&url=http\%3A\%2F\%2Fwww.sci elo.br\%2Fpdf\%2Fpvb\%2Fv37n11\%2F1678-5150-pvb-37-1101261.pdf\&usg=AOvVaw0Z-UZMFuOxXnobZGsOovCH. 
MARTINS, R. P.; SILVA, J.A.G; NAKAZATO, L.; DUTRA, V.; FILHO, E.S.A. Prevalência e etiologia infecciosa da mastite bovina na microrregião de CuiabáMT. Ciência Animal Brasileira, v. 11, n. 1, p. 181-187, 2010. Disponível em: https://www.revistas.ufg.br/vet/article/view/5085

MARTINS, J.D.; NICOLAU, E.S.; MESQUITA, A.J.; JARDIM, E.A.G.V. Mastite subclínica em rebanhos leiteiros de propriedades rurais de Goiás. Revista Brasileira de Higiene e Sanidade Animal, v.9, n.2, p. 206-214, abr - jun, 2015. Disponível em: http://200.137.217.156/bitstream/ri/12439/5/Artigo\%20\%20Juliana\%20Dias\%20Martins\%20-\%202015.pdf

QUINN, P.J.; MARKEY B.K.; CARTER, M.E.; DONNELLY W.J.; LEONARD F.C. Microbiologia Veterinária e doenças infecciosas. Porto Alegre: Editora Artmed, 512p, 2005.

RIBEIRO, M.G.; LANGONI, H.; DOMINGUES, P.F.; PANTOJA, J.C.F. 2016. Mastite em animais domésticos, p.1155-1205. In: MEGID, J.; RIBEIRO, M.G.; PAES, A.C. (Eds). Doenças Infecciosas em Animais de Produção e de Companhia. Roca, Rio de Janeiro.1272 p, 2016.

RODRIGUES, T.P.; COELHO, M.G.A.P.; SANTOS, E.B; COSTA, I.S.; CORTEZ, M.A.S. Mastite Bovina - Influência na Produção, Composição e Rendimento Industrial do Leite e Derivados. Arquivos de Pesquisa Animal, v.1, n.1, p.14-36, 2018. Disponível em: <www2.ufrb.edu.br > phocadownload , category , 21-volumesano-18-vol1>.

ROUQUAYROL, M.Z., ALMEIDA FILHO, N. Epidemiologia e Saúde. 6. ed. Rio de Janeiro:MEDSI, 2009.

SAAB, A.B.; ZAMPROGNA, T.O.; MIZUKI, T.L.; MARTINI, K.C.; MELLO, P.L.; DA SILVA, A.V.; MARTINS, L.A. Prevalência e etiologia da mastite bovina na região de Nova Tebas, Paraná. Semina: Ciências Agrárias, v. 35, n. 2, março-abril, 2014. Disponível em:

http://www.uel.br/revistas/uel/index.php/semagrarias/article/download/12106/14284

SENHORELLO, I.L.S.; BEZERRA, A.O.; SANTOS, R.P; FERREIRA, P.G; STARLING, R.Z. et al. Prevalência, etiologia, sensibilidade microbiana e fatores de risco associados à mastite no rebanho leiteiro bovino do Município de Alegre, Espírito Santo, Brasil. PUBVET, Londrina, v. 7, n. 22, Edição 245, Art. 1619, Novembro, 2013. Disponível em:

http://www.pubvet.com.br/uploads/96cec2eb4ae644b21fe98ef2289b8113.pdf 
TOZZETTI, D. S.; BATAIER, M.B.N; ALMEIDA, L.R. Prevenção, controle e tratamento das mastites bovinas-revisão de literatura. Revista científica eletrônica de medicina veterinária, v. 6, n. 10, 2008. Disponível em: $<$ http://faef.revista.inf.br/imagens_arquivos/arquivos_destaque/YFbjMNrGCotOL73_2 013-5-28-15-25-40.pdf>.

VALLIN, V. M.; BELOTI, V.; BATTAGLINI, A.P.P; TAMANINI, R.; FAGNANI, R. et al. Melhoria da qualidade do leite a partir da implantação de boas práticas de higiene na ordenha em 19 municípios da região central do Paraná. Revista Semina: Ciências Agrárias, Londrina, v. 30, n.1, p. 181 - 188, jan./mar. 2009.

ZIMERMANN, K.F.; ARAUJO, M.E.M Mastite bovina: agentes etiológicos e susceptibilidade a antimicrobianos. Campo Digital, v. 12, n. 1, 2017. Disponível em: http://revista2.grupointegrado.br/revista/index.php/campodigital/article/view/2015 